\title{
The Model of Sequential Brief-Adlerian Psychodynamic Psychotherapy (SB-APP): Specific Features in the Treatment of Borderline Personality Disorder
}

\author{
Andrea Ferrero $^{1 凶}$
}

\begin{abstract}
Sequential Brief-Adlerian Psychodynamic Psychotherapy (SB-APP) is a timelimited (40 weekly sessions) psychotherapy for a wide range of psychic disorders, delivered in sequential and repeatable module (in each module a different therapist is involved). Its specific features in the treatment of Borderline Personality Disorder (BPD) are presented, concerning setting, technique and therapist's emotional attitude. Four Personality Functioning Levels (PFLs) are focused, in order to provide targeted interventions for more homogeneous subsets of BPD patients. PFLs are assessed by evaluating symptoms, quality of interpersonal relationships, overall social behaviours, cognitive and emotional patterns, and defense mechanisms. Two clinical vignettes describe how SB-APP strategies vary according to patient's PFLs, also with respect to the predetermined treatment end. Preliminary reports of SB-APP effectiveness in the treatment of BPD are summarized and discussed.
\end{abstract}

Keywords: borderline personality disorder, personality functioning levels, time limited psychotherapy, Sequential Brief-Adlerian Psychodynamic Psychotherapy

According to the literature, Borderline Personality Disorder (BPD) is characterized by self-other representational disturbance (Bender \& Skodol, 2007), affect dysregulation and impulsivity with risk of suicide (Herpertz, 2011), severe and persistent impairment in social functioning (Gunderson et al., 2011). The scientific literature suggests that BPD core features should be carefully detected in order to provide patients with a consistent, effective treatment (Zanarini, 2009).

\section{Remarks on BPD Psychopathology}

The cornerstone of the psychodynamic approach to personality disorders is that descriptive features of personality pathology that characterize a specific

\footnotetext{
${ }^{1}$ Psychotherapy Unit, Mental Health Department, Health District TO-4, Settimo Hospital, Settimo Torinese, Turin, Italy.

$\square$ Correspondence concerning this article should be addressed to Andrea Ferrero, Psychotherapy Unit, Mental Health Department, Health District TO-4, Settimo Hospital, Settimo Torinese, Turin, Italy. Email: andfer52@hotmail.com
}

personality disorder should reflect the nature and the organization of underlying psychological structures (Caligor \& Clarkin, 2010). According to the biopsycho-social model of psychiatric disorders (Fassino, Abbate Daga, \& Leombruni, 2007), the following BPD pathogenic factors are considered (Fassino, Amianto, \& Ferrero, 2008; Ferrero, 2009; Leichsenring, Leibing, Kruse, New, \& Leweke, 2011; Livesley, 2008): a) vulnerability, b) relevance of significant life events and c) personality dynamic organization.

a) Concerning vulnerability, both genetic and environmental factors affect the risk of BPD (Kendler et al., 2008). More in detail, considering the altered modalities of processing brain functions, in BPD patients it is possible to observe affective instability, a low threshold for impulsive aggressiveness and impairments in cognitive and emotional empathy (Herpertz, 2011; Wolf et al., 2011). These findings thus support a conceptualization of BPD that includes deficits in both inferring others' mental states and being emotionally attuned to another person (Dziobek et al., 2011).

These alterations in critical regulatory domains influence the way representations of self and others 
are internalized (Siever \& Weinstein, 2009). Moreover, psychosocial vulnerabilities have to be considered as mainly rooted in early defective or conflicting experiences. According to an Adlerian psychodynamic model, an adequate development of community feeling, that proceeds from a good quality of primary tenderness relationships (Bolterauer, 1982), has to be considered a favorable factor of selfcohesion and identity. In contrast, depriving or conflictive experiences during childhood may permanently disturb the relational and psychological balance of the individual.

We mould our mind initially in our parents' and other attachment figures' minds. The parent's ability to be responsive to the child, that is to mirror his or her internal state, is the 'core' of affect regulation (Fonagy \& Target, 2007).

Thus, disorganization of the attachment system during infancy (Fonagy, Luyten, Batenian, Gergely, Strathearn, Target, \& Allison, 2010) predisposes to separateness intolerance, as a core item of BPD pathology (Choi-Kain, Fitzmaurice, Zanarini, Laverdière, \& Gunderson, 2009; Steele \& Siever, 2010).

b) Individual vulnerability and adverse life events may interact to lead to the disorder (Leichsenring et al., 2011), but the role of trauma in the BPD development remains unclear. Although recent studies suggest that BPD is not a trauma-spectrum disorder and that it is biologically distinct from posttraumatic stress disorder, high rates of childhood abuse and neglect do exist for individuals with personality dysfunctions. Clusters of personality symptoms seem to be unrelated to specific abuses but they may relate to more enduring traumatic aspects of interpersonal and family environments in childhood (Goodman, New, \& Siever, 2004).

Adverse non traumatic life events provoking symptoms are not likely to be detected, since their relevance is not directly depending on their real impact, but on their symbolic significance (Adler, 1912). Current social and family dynamics usually play an important role in the pathogenesis of BPD (Rovera, 1996). The identity diffusion observed in these patients must be understood in relation not only to the individual patient's history and inner structures but also to contemporary post-modern culture and social organization (Lasch, 1991; Jørgensen, 2006). It is to be hoped that research on the cross-cultural and intracultural variability between different psychiatric diagnostic groups (Sundbom, Jacobsson, Kullgren, \& Penavo, 1998) will be further developed.

c) However, the assumption of diathesis-stress model with traumatization as a necessary but etiologically insufficient condition seems justified (Driessen et al., 2002). The potential role of specific life events in BPD pathology should be assumed to result from the interplay between psychosocial adversities and a maladaptive structure of personality (Livesley, 2008). Consequently, personality disor- ders should be also regarded as disorders of adaptation and compensation (Adler, 1912), as extreme personality traits are not ipso facto dysfunctional (Svrakic, Lecic-Tosevski, \& Divac-Jovanovic, 2009). We consider that dynamic personality organization corresponds to the whole set of mechanisms of adaptation and defense of the individual, both in facing inner experiences and interacting with others (Morbach, 2007). The evaluation of the defense mechanisms is one of the most promising fields in the psychodynamically oriented empirical research on personality disorders (Bond \& Perry, 2004; Lingiardi et al., 1999; Lingiardi \& Madeddu, 2002) and, in contrast to other approaches, a dimensional model based on defense mechanisms is easily applied to personality disorders (Bowins, 2010). Considering patient clinical variables, we refer (Fassino et al., 2008) to three pathological personality organizations, according to Paulina Kernberg (P. F. Kernberg, 1994): Psychotic Personality Organization (PPO), Borderline Personality Organization (BPO) and Neurotic Personality Organization (NPO).

The patients with BPO have an unstable identity: The self-other image is preserved by rigid defenses aimed at safeguarding the subject from the perception of ambivalence (Ferrero, 2009). Borderline defenses are characterized by: splitting, denial, idealization and devaluation, projective identification, omnipotent control and acting-out (P. F. Kernberg, 1994).

It is not only BPD but also other prevalent and severe psychiatric disorders that are related to BPO (Van Asselt, Dirksen, Arntz, \& Severens, 2007) and a lot of studies (Presniak, Olson, \& Macgregor, 2010) demonstrate important differences in defense use between borderline and other axis II patients across both observer interviews and self-report measures (Defense Style Questionnaire-DSQ; Andrews, Singh, \& Bond, 1993).

More specifically, according to recent research (Zanarini, Weingeroff, \& Frankenburg, 2009), borderline patients have significantly higher DSQ scores on some immature defenses (Vaillant, Bond, \& Vaillant, 1986), namely acting out, emotional hypochondriasis, passive aggression and projection, on some imaging-distorting defenses (Perry \& Cooper, 1986), namely projective identification and splitting, and on undoing, that is a neurotic-level defense (Vaillant et al., 1986). Particularly, a trio of defenses (acting out, emotional hypochondriasis and undoing) may explain some core clinical aspects of BPD (impulsivity, demandingness and making amends). On the contrary, narcissistic defenses (Perry \& Cooper, 1986) associated to BPO, such as devaluation, omnipotence and primitive idealization, seem not strongly related to borderline psychopathology.

\section{Treatment Problematic Issues}

Clinical experience supported by the systematic review of recent literature shows that the severity of 
BPD symptoms and of social maladjustment is not sufficiently influenced by medication (Stoffers et al., 2010). There is some evidence that in order to avoid this pattern of high use of drugs, the lack of effective drug treatments should be balanced by the application of structured psychotherapies within the available treatment options (Bender et al., 2006).

Currently, both cognitive-behavioral and psychodynamic specific psychotherapies for borderline disorders seem effective to reduce the severity of psychopathology (Zanarini, 2009). Some evidence suggests that long-term treatments could be useful in avoiding premature ruptures in the therapeutic alliance with patients with attachment disturbances (Choi-Kain et al., 2009), early defective and conflicting experiences. Nevertheless these approaches are often unavailable due to insufficient resources and do not resemble treatment as usual (TAU), which is characterized in general by pharmacotherapy, rehabilitative interventions and unstructured psychological supports, although no research has examined it in detail (Paris, 2010).

On the other hand, shorter psychotherapeutic treatments, which are currently effective for borderline patients, are useful in order to address their specific disruptive behaviors, but they are less effective in reducing their heavy Mental Health Services (MHS) use, that is possibly related to core affective features, such as intolerance of being alone and conflicts over dependency (Choi-Kain, Zanarini, Frankeburg, Fitzmaurice, \& Reich, 2010).

In the current literature (Zanarini, 2009; Paris, 2010) the development of briefer forms of treatments that are less complex and have a lower frequency than long term psychodynamic psychotherapies is recommended, in order both to adapt to the extensive problems of borderline patients and to reduce their heavy and non-therapeutic MHS use. However, literature data concerning time-limited psychotherapy effectiveness with BPD patients is not univocal at all. Thus, some possible negative consequences are as follows: low treatment intensity (Leichsenring, 2005), deconstruction of the working alliance (Gunderson, 2008) and risk of traumatic abandon (Koekkoek, van Meijel, Schene, \& Hutschemaekers, 2009), due to BPD patients' specific vulnerability (reduced empathy, separateness intolerance) and personality organization (high use of self-other image distorting defenses; Zanarini et al., 2009).

Nevertheless, a time-limited treatment could also enhance some positive factors (Leibovich, 1983; Ferrero \& Simonelli, 2006; Paris, 2007): structuring psychic internal boundaries, since BPD patients have deficient psychic structures and lead chaotic lives (Paris, 2010), decreasing omnipotence, expanding time for assimilation and respecting crisis moments. Furthermore, according to a 10-year longitudinal study on BPD (Choi-Kain et al,. 2010) some behaviorally-oriented features that represent clinical priorities, such as recurrent breakups, sadism, self- harm, demandingness and boundary violations tend to remit quickly and do not need long-term treatments. Finally, drop-out of borderline patients (Sledge, Moras, Hartley, \& Levine, 1990) in timelimited psychotherapy is lower than those in longterm treatments and short-term treatments without any set time limit.

\section{Aims of the Paper}

In order to overcome these problems, a Public Training \& Research Network on Adlerian Psychodynamic Psychotherapy (APP) for Personality Disorders (University of Turin, Neuroscience Department, Psychiatry, Eating Disorders Unit; SAIGA School of Psychotherapy, Turin, Healthcare Agency Turin 4, Department of Mental Health, Psychotherapy Unit) has been operating in Turin since 2004 and its main aim is to propose and test a psychotherapeutic technique for the treatment of BPD, taking into account these following objectives:

a) Accessibility. This refers to MHS efficiency (Paris, 2010; Zanarini, 2009): a time-limited psychotherapy with a low sessions frequency.

b) Ductility. This refers to a model which is not only devoted to treating BPD patients (Paris, 2010; Weinberg et al., 2010).

c) Continuity. This refers to dependence and separation (Koekkoek et al., 2009): psychotherapy as a part of a coherent clinical treatment plan.

d) Specificity. This refers to appropriate patient/treatment matches (Hadjipavlou \& Ogrodniczuk, 2010; Verheul \& Herbrink, 2007): a psychopathology-based psychotherapy.

The aim of this paper is to present Sequential Brief-Adlerian Psychodynamic Psychotherapy (SBAPP) which is a treatment for a wide range of psychiatric disorders (Amianto et al., 2011; Ferrero, 2009; Ferrero \& Simonelli, 2006).

More in detail, the paper aims at describing its specific features in the treatment of $\mathrm{BPD}$, concerning treatment plan and setting, elements of strategies and techniques, therapist's emotional attitude and countertransference. In order to exemplify some aspects and the results of this psychotherapeutic technique we are going to provide you with two clinical vignettes and the outcomes of a preliminary randomized clinical study.

\section{Sequential Brief-Adlerian Psychotherapy (SB-APP)}

SB-APP is a treatment based on overall theory and practice of "Individual Psychology" (IP). The term "Individual Psychology" (IP) refers to the theoretical and clinical contributions to psychotherapy started by Alfred Adler (1870-1937), one of the first 
Viennese psychoanalysts, who separated from Freud in 1911. Adlerian psychology is based on different theoretical foundations compared with psychoanalysis (i.e., the importance of the desire for power and social feelings in the individual's lifestyle and intrapsychic dynamics), but it foreshadows some modern psychoanalytical developments, with particular regard to the intersubjective aspects of psychotherapeutic treatments and the importance of social and cultural environment.

SB-APP is a psychodynamic-oriented therapy. It relates the individual's actual symptoms, maladaptive coping and psychological suffering to unconscious dynamics even though the psychic structure or the symbolic meaning of the patient's communications are not necessarily the main targets of the therapist's interventions (Gorton, 2000).

SB-APP is a time-limited (40 weekly sessions) treatment, delivered in sequential and repeatable modules (a different therapist is involved in each module). Like Dialectical Behavior Therapy-Brief (DBT-B) and Cognitive Behavior Therapy (CBT), SBAPP is a shorter therapy compared to twelve or eighteen-month treatments with Dialectical Behavior Therapy (DBT), Transference Focused Psychotherapy (TFP) and Mentalization Based Treatment $(\mathrm{MBT})$. In this way, SB-APP treatment meets criteria of accessibility.

SB-APP was originally conceived for the treatment of a wide range of personality disorders, with or without DSM IV-TR Axis I disorders comorbidity (excluding schizophrenia and mood bipolar disorder), both in private practice and in public Mental Health Services (MHS), as a part of multidisciplinary patient care. In this way, SB-APP treatment meets criteria of ductility and continuity.

SB-APP treatment varies according to different psychiatric disorders. More specifically, strategies and techniques are focused and tailored according to patients' psychopathological functioning. In this way, SB-APP treatment meets criteria of specificity.

\section{Elements of Treatment Plan and Setting}

In contrast to the treatment of other less severe psychic disorders, SB-APP for BPD patients is usefully delivered as part of a clinical project, which involves another therapist at least, providing overall clinical management, non-scheduled interventions, crisis interventions and pharmacotherapy, when suitable. This proceeds from BPD symptomatology, including impulsive aggressiveness, risk of suicidal attempts, affective instability, demandingness and depression. Nevertheless, when symptoms are particularly severe and numerous, they are better addressed by a multidisciplinary MHS Team (psychiatrists, psychologists, nurses, educators and social workers).

When a double therapist setting is proposed, or when SB-APP is part of a multidisciplinary MHS clinical project, borderline patients have to know the limits of the psychotherapist's role in order to cope with concrete needs, family support and overall clinical necessities. Setting boundaries produces a corrective emotional experience compared to the patient's previous confusing relationships, which are a major source of vulnerability for BPD.

Thus, as suggested by NICE BPD Clinical Guidance (National Institute for Clinical Excellence, 2009), it's necessary to clearly identify roles and responsibilities of all health and social care professionals involved. In this way they can (1) develop a crisis plan in order to identify potential triggers that could lead patients to a crisis and (2) establish how patients can access services in case of urgency. In this regard, regular communications between SBAPP psychotherapist and other healthcare professionals are particularly important.

Furthermore, MHS Teams (psychiatrists, psychologists, nurses and educators) need to be trained in borderline disorders treatment (Kerr, Dent-Brown, \& Parry, 2007) in order to provide coherent care to patients. In our experience in Chivasso, Turin (Italy) this training involves: 1) a preliminary brief educational program concerning borderline disorders etiology, symptoms and care; 2 ) regular supervisions (every 15 days) in order to promote coherent treatment planning; 3) regular case discussions (monthly).

A coherent treatment plan allows the SB-APP therapist to focus his/her attention exclusively on the sessions, that is, on the patient's ability to mentalize, elaborate and avoid dependency and acting out. Comprehensively, a clearly defined treatment structure is appropriate in order to increase cognitive and emotional regulation in BPD patients (Paris, 2010). They need to be informed in detail about treatment setting rules. Particularly, session frequency and duration, psychotherapy objectives, consequences of therapist and patient's absences are clearly defined.

For BPD patients, in whom pathology tends to remit over time, intermittent rather than continuous therapy could represent an option. These patients are allowed and encouraged to take treatment breaks, but at the same time they may start a new psychotherapy module if further problems need more elaboration or new issues arise (Paris, 2007). If a second (or further) SB-APP module is useful, the patient must first work on the separation and loss of the previous therapist, processing idealization or devaluation.

\section{Elements of Treatment Strategies and Techniques}

Some brief remarks on SB-APP strategies and techniques for the treatment of BPD will be proposed here (Amianto et al., 2011; Fassino et al., 2008; Ferrero, 2009; Ferrero \& Simonelli, 2006;). Since BPD are characterized by awkward means of managing and expressing their inner pain, which is behavioral and interpersonal in nature (Zanarini \& 
Frakenburg, 2007), SB-APP takes particularly into account IP considerations about relevance of socialrelational dynamics in maintaining mental disorders. When patients talk about events that occurred in their life, SB-APP therapists have to recognize how these stories also represent significant examples of their lifestyle dynamics.

Evidence shows that it is important for therapists to focus their interventions on patient's affect, relational patterns and the "here and now" of the relationship (Lingiardi, Colli, Gentile, \& Tanzilli, 2011) before working on the symbolic meaning of the narrative, considering BPD impairment in cognitive and emotional empathy, low levels of mentalization and altered representations of self and others. Consequently, SB-APP therapists first give greater importance to the present than to the past.

On the contrary, compared to classical psychoanalytically-oriented psychotherapies, they do not encourage free associations, because they don't seem to be useful for patients who are constantly in the throes of emotion dysregulation. Moreover, unlike what happens in interpersonal psychotherapies, the SB-APP therapist doesn't limit his/her attention to facts and how to cope with them, because BPD patients have to learn their feelings better before starting to think about alternative solutions to their problems and projects for the future. The therapist chooses whether to search for solutions of existential problems or to perform a reality test on the current traumatic situation the patient is experiencing, or to recall and elaborate early traumas. These issues are combined in a creative perspective according to the patient's personal patterns of apperception (Adler, 1912) and interpretation of reality (Tenbrink, 1998). Particularly, traumatized patients can't cope with stressful thoughts and become increasingly activated and disturbed, when they are re-exposed to trauma (Koenigsberg, 2009).

In general, BPD patients react more to emotional cues if borderline specific schemas are activated (Limberg, Barnow, Freyberger, \& Hamm, 2011). The SB-APP therapist may help the patient to tolerate the more stressful external events, both for their severity and their symbolic meaning. For example, this goal can be achieved by attributing a meaning and fostering the acceptance of unavoidable events. Furthermore, at a deeper level, the therapist may lead the patient not to be too affected by the intrapsychic stimuli that are related to those adverse events.

Technical Instruments Axis (TI-AX). The therapist's responses to questions posed by the patient's pathology benefit from the use of Technical Instruments (TI). To this end, SB-APP uses the system proposed by the Menninger Clinic Treatment Interventions Project (Gabbard, 2000) for describing the technical instruments of psychotherapy. This classification is only used to describe TIs and the way they treat the material presented during therapy sessions, and not to distinguish their higher or lower power to induce a change (i.e., interpretations are gold, praises are lead). Thus a distinction between exploratory and validating technical instruments along a functional dimension (TI-AX) was made.

Exploratory TIs promote the connection between patient's verbalizations and other unconscious, subconscious or conscious elements, respectively by: interpretation $\left(\mathrm{TI}_{1}\right)$, confrontation $\left(\mathrm{TI}_{2}\right)$ and clarification $\left(\mathrm{TI}_{3}\right)$. Validating TIs promote the identification and importance of specific experiences, situations, or behaviours (empathic validation, $\mathrm{TI}_{5}$; advice and praise, $\mathrm{TI}_{6}$; confirmation and prescription, $\left.\mathrm{TI}_{7}\right)$. The encouragement to elaborate $\left(\mathrm{TI}_{4}\right)$, that sometimes is expressed through the therapist's silence, seems inclusively placed in the middle of the TIs continuum.

Intensive-Supportive Axis (IS-AX). Starting from the patient's request to be helped to change its own clinical condition and increase well-being, psychotherapy has to be conceived as a helping profession. Namely, both into the therapist and patient, an expectation is developing so that psychic pain may be appeased by an emotive correcting experience. More in detail, past relational modalities of the patient will be variously corroborated or hindered during the sessions.

According to Alfred Adler, therapists' responses constitute a way to manage the relational distance (Adler, 1920) during the treatment, including mutual feelings of sharing, release or opposition. Closeness or remoteness are generated by patients' and therapists' experience and recognition of repetitive ways of relating to others (including unconscious aspects of transference).

An expert therapist has to be adequately flexible and able to modify the psychotherapeutic technique according to the patient's needs. The aim is to determine which combinations are expected to promote best outcomes for specific relational problems of BPD patients: affective instability, impulsivity and acting out, demandingness, intolerance to separation. SB-APP therapist will modulate the emotive correcting experience according to intensive strategies or supportive strategies. They differ along a continuum (IS-AX) at the rate of prevailing quality of the relationship.

Intensive strategy is characterized by a dialogic working alliance (WA), while the therapist is fostering patients' elaborations rather than providing one's own opinions. The aim is increasing patient's attitudes to attention, confidence and comprehension of his difficulties, as forerunners of change. Supportive strategy is characterized by a supportive WA, while therapist's contributions are prevailing. The aim is providing new solutions to the patients problems.

Difficulties in building a good WA with therapist 
were frequently found in subjects affected by BPD, due to their poor quality of object relations (Piper et al., 2004), which characterizes the patients lifelong patterns of relationship. More in detail, selfother representations are distorted in BPD patients, as a consequence both of their specific vulnerability and defense mechanisms (BPO). Reducing risk of identity diffusion is an early and primary therapist's task with these subjects. Consequently, supportive treatment strategy do not usefully deals with advices and praises $\left(\mathrm{TI}_{6}\right)$, but with clarifications $\left(\mathrm{TI}_{3}\right)$, empathic validations $\left(\mathrm{TI}_{5}\right)$ and confirmations $\left(\mathrm{TI}_{7}\right)$.

Analogously, intensive treatment strategy mainly deals with a possibility that BPD patients' thoughts and emotions can be expressed. Therapist has to recognize them before using confrontations $\left(\mathrm{TI}_{2}\right)$ and interpretations $\left(\mathrm{TI}_{1}\right)$.

Mutative-Conservative Axis (MC-AX). In SBAPP, the therapist's strategies differentiate along another axis based on the patient's main psychopathological functioning modalities. This applies to supportive therapies as well as to intensive therapies.

The importance of a detailed understanding of patients' intrapsychic organization was early emphasised by Alfred Adler as essential for performing psychotherapy (Adler, 1920). Actual research shows that both quality of objects relations and defense mechanisms seem to predict the outcome of therapist's specific technical interventions (Hersoug, Høglend, \& Bøgwald, 2004; Piper, Ogrodniczuk, \& Joyce, 2004). Consequently, it is recommended that psychotherapy strategies and techniques are based on a careful formulation of the psychodynamics of the patient's presenting complaint, especially when patients with BPD and other personality disorders are treated (Hadjipavlou \& Ogrodniczuk, 2010; Verheul \& Herbrink, 2007). Mutative strategy seeks to provoke a change in lifestyle and personality organization by changing at least some of the defense mechanisms that are significantly connected with the pathology. Conservative strategy aims to respect and strengthen the patient's compensatory mechanisms, and more specifically it keeps the defenses functioning in a more evolved, healthier and adaptive way for the subject and for other people.

SB-APP doesn't assign a priori to each TI a meaning in terms of intensive $v s$ supportive strategy or conservative $v s$ mutative effectiveness, which depends on patient's pathology and personality organization. Therefore, SB-APP is a psychopathologybased psychotherapy. As opposed to some other psychodynamically oriented psychotherapies, particularly insight-enhancing, SB-APP can combine directive $v s$ nondirective treatment issues according to the assessment of the patient's defense mechanisms and their role on the psychic balance.

Therapist's interventions should preserve more adaptive defenses and work on poorly effective ones, which can lead to at-risk behaviors and decrease self- esteem. Differently from NPO patients, advices and praises $\left(\mathrm{TI}_{6}\right)$ are pretty useless with BPD patients who consistently distort their interpersonal environment, as well as interpretations $\left(\mathrm{TI}_{1}\right)$ are not necessarily useful for change (Paris, 2010). Furthermore, clarifications $\left(\mathrm{TI}_{3}\right)$ and empathic validations $\left(\mathrm{TI}_{5}\right)$ are essential for BPD patients who are sensitive to the slightest hint of invalidation, while confrontations $\left(\mathrm{TI}_{2}\right)$ have to be used tactfully (Paris, 2010), because they can be addressed to splitting defenses.

Specifically concerning transference interpretations, they may decrease WA and be detrimental with patients with a higher levels of defensive functioning. On the contrary, a higher use of interpretations could increase WA in patients with a lower level of defensive functioning, as happens in BPD patients (Hersoug, 2004).

\section{Therapist's Emotional Attitude and Counter-transference}

The way borderline patients function is likely to burden the therapist. More in detail, patients intruding, frightening and abandoning modalities are usually re-experienced in the relationship with the therapist. A careful recognition of countertransference is thus necessary, as it develops in the interpersonal therapeutic process (Bender, 2005). Particular attention should be paid to patient's self-other split images that could affect therapist's emotional attitudes and thoughts (Ferrero, 1995; PresslichTitscher, 1997), by inducing discouragement or omnipotence.

Projective identification as well cannot be separated from dealing with countertransference, since patients unconsciously try to make the therapist take over certain roles and affects. This acting out is of great importance for a deepened understanding of the patient (Matschiner-Zollner, 2004). Furthermore, in case of treatment drop-out, which can frequently occur with borderline patients, the analysis of countertransference can provide a deeper understanding of the psychodynamic causes that led to the premature ending (White, 2007).

In conclusion, the usefulness of explicit technical issues may be conceived in order to increase the awareness of which rules determine the therapist's actions during psychotherapy. In contrast, a strict adherence to a manualized description of the processes could be misleading.

\section{Personality Functioning Levels}

Patient's characteristics that have an impact on outcomes are suitable to be detected (Delaney, Yeomans, Stone, \& Haran, 2008), in order to provide targeted interventions for more homogeneous subsets of BPD (Lenzenweger, Clarkin, Yeomans, Kernberg, \& Levy, 2008; Mc Closkey et al., 2009). 
Table 1. Main psychopathological items in the description of different PFLs in BPD

\begin{tabular}{|c|c|c|c|c|}
\hline Items & PFL I & PFL II & PFL III & PFL IV \\
\hline ID & $\begin{array}{l}\text { Partial symbolic } \\
\text { and pre-symbolic } \\
\text { representations of } \\
\text { self (nuclear identity) }\end{array}$ & $\begin{array}{l}\text { Splitting and } \\
\text { idealization of self and } \\
\text { others representations } \\
\text { (split identity) }\end{array}$ & $\begin{array}{l}\text { Avoiding consequences } \\
\text { of being aware of one's } \\
\text { own and others contra- } \\
\text { dictory qualities (anti- } \\
\text { ambivalent identity) }\end{array}$ & $\begin{array}{l}\text { Anti-ambivalent and } \\
\text { hyper-ambivalent aspects } \\
\text { of identity }\end{array}$ \\
\hline $\mathrm{CO}$ & $\begin{array}{l}\text { Impaired } \\
\text { comprehension of } \\
\text { one's own and others } \\
\text { behaviours in terms of } \\
\text { thoughts, desires and } \\
\text { expectations }\end{array}$ & $\begin{array}{l}\text { Comprehension of } \\
\text { one's own and others } \\
\text { behaviours, thoughts } \\
\text { and emotions, only if } \\
\text { they do not upset self- } \\
\text { image }\end{array}$ & $\begin{array}{l}\text { Concrete thought } \\
\text { When divergent } \\
\text { motivations stem } \\
\text { from comprehension } \\
\text { of one's own and others } \\
\text { behaviours, thoughts } \\
\text { and emotions, they are } \\
\text { not integrated }\end{array}$ & $\begin{array}{l}\text { Poor tolerance of } \\
\text { contradictory aspects } \\
\text { of one's own and others } \\
\text { behaviours, thoughts and } \\
\text { emotions }\end{array}$ \\
\hline EM & $\begin{array}{l}\text { Anger, depression, } \\
\text { feelings of emptiness }\end{array}$ & $\begin{array}{l}\text { Irritation, depression, } \\
\text { feelings of emptiness }\end{array}$ & $\begin{array}{l}\text { Anger recognition, } \\
\text { shame, depression, } \\
\text { feeling of emptiness }\end{array}$ & $\begin{array}{l}\text { Guilt, sadness, } \\
\text { dissatisfaction, } \\
\text { feelings of emptiness }\end{array}$ \\
\hline AR & $\begin{array}{l}\text { Self-damaging and/or } \\
\text { alienating behaviours }\end{array}$ & $\begin{array}{l}\text { Threats of self-harming } \\
\text { and/or alienating } \\
\text { behaviours }\end{array}$ & $\begin{array}{l}\text { Ideas of self-harming } \\
\text { and/or alienating } \\
\text { behaviours }\end{array}$ & $\begin{array}{l}\text { At some extent, impulsive } \\
\text { and/or blocked } \\
\text { behaviours }\end{array}$ \\
\hline SO & $\begin{array}{l}\text { Poor capability to } \\
\text { manage social } \\
\text { autonomies }\end{array}$ & $\begin{array}{l}\text { Unstable tolerance for } \\
\text { engagements and } \\
\text { relations }\end{array}$ & $\begin{array}{l}\text { Attempts to work } \\
\text { Low tolerance of } \\
\text { loneliness }\end{array}$ & $\begin{array}{l}\text { Poor flexibility in } \\
\text { distancing or approaching } \\
\text { others }\end{array}$ \\
\hline $\mathrm{RE}$ & $\begin{array}{l}\text { Demanding immediate } \\
\text { availability versus } \\
\text { oppositional tendencies } \\
\text { with the therapist }\end{array}$ & $\begin{array}{l}\text { Dependent and } \\
\text { idealized relationship } \\
\text { with therapist }\end{array}$ & $\begin{array}{l}\text { Dependent relationship } \\
\text { with therapist }\end{array}$ & $\begin{array}{l}\text { Supportive relationship } \\
\text { with therapist }\end{array}$ \\
\hline
\end{tabular}

Note BPD = borderline personality disorder; $\mathrm{PFL}=$ personality functioning level; $\mathrm{ID}=$ identity disturbance; $\mathrm{CO}=\mathrm{cogni}-$ tive distortion; $\mathrm{EM}=$ negative emotions; $\mathrm{AR}=$ action and behavior dysregulation; $\mathrm{SO}=$ social skills impairment; $\mathrm{RE}=$ quality of therapeutic relationship.

The quality and rapidity of change are influenced by patients' global functioning, including level of defences, quality of the interpersonal relationships, life skills and specific interpersonal problems. Various taxonomy approaches were proposed for reducing the heterogeneity observed among BPD (Lenzenweger et al., 2008).

SB-APP treatment for BPD is specifically focused on four personality functioning levels ( $\mathrm{PFL}$ ), which are differentiated by "prototypical descriptions" (Shedler \& Westen, 1998) which refer to five psychopathological items (Amianto et al., 2011; Ferrero, 2009; Ferrero et al., 2006): identity disturbance (ID), cognitive distortion (CO), negative emotions (EM), action and behavior dysregulation (AR), social skills impairment (SO). In addition, they refer to one item concerning the quality of therapeutic relationship (RE). Patient's PFLs psychopathological items (ID, CO, EM, AR and SO) are consistent with the conceptual framework proposed by Livesley that describes BPD based on empirical studies of the phenotypic structure and genetic architecture of personality (Livesley, 2008) and with other recent studies on the main features of BPD (Bender \& Skodol, 2007; Distel et al., 2010; Jørgensen, 2006).

Different PFLs characteristics are briefly summarized in Table 1. Patients with PFL I, II and III are more severe and have a prevailing $\mathrm{BPO}$, while patients with PFL IV are less severe and are characterized by the presence of elements of BPO and NPO. Concerning the overall goals of treatment, at PFL I SB-APP is mainly focused on preventing disruptive acting-out by providing reality testing, by strengthening self-reflective functions and identity. At PFL II, the approach is focused on increasing empathy through validating thoughts and emotions and de- 
creasing egocentrism, idealization and dependence. At PFL III, therapy aims at reducing the sense of emptiness and increasing continuity and adaptation. Finally, at PFL IV, therapy attempts to develop increased tolerance for ambivalence, help patients overcome conflicts, enhance autonomy, and increase positive attitudes toward projects.

\section{Two Clinical Vignettes}

The following clinical vignettes describe the way in which SB-APP therapists differently face some treatment stages according to different PFL patients, paying particular attention to the end of psychotherapy.

\section{Clinical Vignette No. 1: Borderline Personality Disorder (BPD) and BPO (PFL III and IV)}

During psychotherapy, fear of separation deals with WA in a wide range of subjects with Cluster $\mathrm{C}$ (anxious-fearful) Personality Disorders and NPO. Their self-other image is settled and coherent, but contradictions, conflicts and doubts lead the patient to search for validation and acceptance. Patients are emotionally inhibited and averse to interpersonal conflict (Bender, 2005): So, they are frequently anxious and buried: Even if it is consciously accepted, aggressiveness and pain relating to relationship with the therapist are likely to be repressed. What is usefully done with neurotics, does not seem to be suitable with BPO patients.

Inadequate primary tenderness (Bolterauer, 1982) relationships, that represent a specific BPD patient's psychosocial vulnerability which is connected to a failure of identity construction, lead to a severe disindividuation distress in these patients, while they're facing adverse or complex life events.

Due to their immature and imaging-distorting defense mechanism (Zanarini et al., 2009), borderline patients have unstable self-other images, so their interaction with others is organized around a fundamental need for care that is felt to be necessary for basic functioning (Bender \& Skodol, 2007). Consequently, patients are often incoherent, unstable and impulsive.

a) With regard to the treatment plan, the SB-APP therapist has to repeatedly protect setting integrity, facing patients' disruptive acting-out. Therefore, double-therapist setting is strongly recommended in these cases.

b) Concerning treatment strategy and technique, at PFL III, subjects are largely engaged in denying that self-other contradictory images should be considered relevant for their life and behaviors, since at PFL IV this attitude only appears when facing specific tearing emotions and situations. The patient is dependent on the therapist, thus formally accepting his possible absence. The patient's hyperactivity and concrete way of thinking compensate for a lack of symbolic function, which was predisposed by insecure and disorganized attachment during infancy. Consequently, systematic consideration should be paid to all the patient's acting-out and the discontinuities in his/her social relationships involving intimacy. Greater attention should be devoted to setting disruptions during the treatment: These aspects have to be pointed out, explained and foreshadowed in detail, using empathic validation and clarifications. In this way the patient can progressively become aware of the therapist's acceptance when his own uniqueness and diversity are evident, even in the presence of opposition and aggressiveness. This will appear as fundamental when the therapy ends.

c) This process does not relate exclusively to therapists' technique but it also deeply involves emotions and countertransference. Since ambivalence is too frightening for the patient; therapists might tolerate it by avoiding non-integrated intrusive or abandoning reactions.

Clinical vignette. R.F. is a 45-year woman with $B P D$, suffering from acute episodes of anxiety with transient dissociation of reality after her husband died in a road accident. During adolescence, she was repeatedly abused by her father; subsequently, when she got married, she had three children, but the eldest of them suffered from schizophrenia. Early in the treatment, at session 4, R.F. said to her male therapist: "I'm in trouble because I feel I am in love with my son's psychiatrist." The therapist, refraining from interpreting the symbolic way in which the patient communicated her anguish at being newly involved in sexualized relationships with men from whom she was expecting care, simply affirmed: "I'm confident that you will be able to control your feelings and emotions, according to your will and values." Thus the therapist was primarily supportive and conservative, strengthening the patient's rationalizations instead of her tendencies to use projective identification. At session 6, R.F. showed the therapist a drawing in which a penis was clearly represented; she said: "It's incredible: I was only tracing some colored lines without importance, in order to relax." Then some more aspects of conflicting feelings about father's sexual abuses were explored (by clarifications). After session 15, R.F. was repeatedly explaining to the therapist her incoherent feelings about of her son's therapist. Then, at session 19, she said with an ironic smile: "I'm not so lucky! When I'm starting to forget him, I casually meet him somewhere!" (that was quite true, because they shared many friends and occasions of social encounters.) The therapist perceived that R.F. might preliminary hold in her mind different images of self and her son's psychiatrist (though not of her father) and encouraged acceptance and elaboration of such conflicting thoughts. Two sessions later, R.F. 
commented favorably on the treatment course, underlining her ability to think and feel something new, even when not very clear; the therapist, again using empathic validation and praise, answered the patient: "I think it's really hard to explore some vague and complex feeling, but it could lead to an enrichment of your peace and wellness." Even when adopting a mutative strategy and working on splitting defenses, the therapist remained supportive during the whole treatment. At the end of the therapy, an excessive importance of remembering the past was discouraged by the therapist. Moreover, the patient was authorized, with the therapist's advice and supportive strategy, to take a more confident attitude towards her possibilities of thinking and facing life events. In this way, R.F. became sufficiently capable to accept the perspective of the end of the therapy and to look up to the future. Nevertheless, considering that patients at PFL III and IV are usually able to understand others in a constructed rational way rather than in an instinctive and affective one, the therapist gave the patient the opportunity of a a single follow-up session after three months, in order to share the understanding of her difficulties in parting and to reinforce the belief in mutual understanding. Balancing mutative interventions towards some splitting defenses with a supportive emotional experience seems to be the best way to protect the patients from the anguish of being a separated individual at the end of psychotherapy.

\section{Clinical Vignette No. 2: Borderline Personality Disorder (BPD) and BPO (PFL I and II)}

However, patients with lower borderline personality organization (PFL I and II) need a different treatment strategy, as they preserve identity by separately representing different aspects of their contradictory experiences.

a) With regard to the treatment plan, a multidisciplinary therapeutic team is necessary to treat patients at PFL I or II. The treatment setting has to be explained in detail before starting SB-APP sessions. Patients are informed that the psychotherapist will be at their disposal only during the sessions and other therapists will be available in order to cope with any clinical emergencies and provide pharmacological therapy or concrete help.

b) Concerning treatment strategy and technique, at PFL I and II, therapists have to consider that patients unconsciously fear that their fragile identity might collapse. In this regard, empathic validation $\left(\mathrm{TI}_{5}\right)$ and, to a lesser degree, clarification $\left(\mathrm{TI}_{3}\right)$ and affirmation $\left(\mathrm{TI}_{7}\right)$ can effectively convey constructive experiences concerning the precarious cohesion of self and the patient's incapacity to think in the presence of others, and to tolerate the therapist as a separate existence (Ferrero, 2009).

c) Therapists' emotions are deeply affected by the patients. All of them, including SB-APP therapist, has to cope with conflicting, split and projective aspects of the patients. So, they need to share and compare their conviction and feelings about the patient, in order to build up a clear therapeutic relationship. Therapists' goals should be viewed by the patient as being strictly on the same wavelength, as part of the same project. An idealized dependence is perhaps the only possibility for such patients to be involved in a trustful therapeutic relationship. Nevertheless, the contagion of patients' idealization has to be prevented by a constant attention to the therapist's transient euphoric emotions.

However, when dependence is established on a group of multiple caregivers playing integrated unequivocal roles, patients may progressively experience diversity within a coherent whole, as protective limits. So patients could also become more confident that they would be helped in other ways after the end of psychotherapy, if necessary.

Clinical vignette. B.C. is a young woman aged 31 , with a severe BPD characterized by acute anguish attacks, intermittent bulimia and alcohol abuse, incoherent affective and working projects, recurrent self-harming behaviors (cuts on arms, legs, abdomen and even breast). She is the third child of a couple of parents which are described by the patient as weak and dependent on the opinions and advice of her elder sister, who is living in America. In order to illustrate her conviction, she said to her psychiatrist during a visit: "Once upon a time, when my sister told my parents that it would be better to ignore me, because I'm false and manipulating, they agreed without any opposition and I had to temporarily leave my family home." On the other hand, B.C.'s mother used to complain: "I did all I could to help her, but it was all in vain!"

B.C. was first receiving treatment at Mental Health Service (MHS). Very soon, a daily phleboclysis with benzodiazepines and antipsychotics was prescribed in order to reduce her repeated cutting behaviors. Only during the weekend this therapy was suspended when the patient successfully served as a disc jockey in another village not so far from home. Since this pharmacologic treatment didn't have any efficacy, MHS nurses suggested that would be best to increase it, administering therapy also during the weekend. After two month B.C. started a SB-APP module. After three months B.C. said to her psychiatrist: "I'm very anxious because my sister is coming from America and while she is here she will share my home with me and my parents!" The psychiatrist only reassured B.C. of his own availability and support, but he took no measures to deal with the patient's situation. Next evening an anxiety crisis led the patient to be taken into hospital (also as a symbolic secure shelter).

B.C.'s personality functioning level is very disadaptive and her mentalization attitudes are very poor. Unfortunately, MHS care was repeating the mother's way of care, characterized by a generous 
but not selective attention to the patient's needs. So B.C. was initially perceiving psychiatrist and nurses as abandonic and confusing. She became more reactive and less compliant to MHS treatments and more attached to the psychotherapist. In order to restore B.C.'s compliance, a clear change in MHS care planning (with a supervisor's help) was first necessary, before the psychotherapist could describe and explain to the patient the emotions and feelings that had occurred (by using empathic validation and clarification). During a session after the inpatient treatment, B.C. said: "My mother never understood what I felt. For example, once I had a violent fever and she recommended me to eat well... Eating was good for everything!" The therapist responded: "Now you're doing the same: when you're searching for help, bulimia or cuts are good for everything!" A better working alliance with the MHS team was subsequently useful in permit separation from the psychotherapist at the end of SB-APP module. A prolonged dependence on a therapeutic team with a positive reflective functioning seems the most suitable protection for psychotherapeutic work with such severe patients, in order to achieve a better self-image integration.

\section{SB-APP application preliminary reports}

A preliminary clinical randomized study (Amianto et al., 2011) showed evidence of SB-APP effectiveness in a sample of patients with BPD. Eighty-one outpatients were enrolled in Mental Health Center of Chivasso (Turin, Italy). They had been treated and clinically managed for at least one year. Thirty-five outpatients who met inclusion criteria were randomly assigned to two treatment groups: 1) Supervised Team Management Group (STM; $n=17), 2$ ) SB-APP Group (SB-APP; $n=18$ ) and then compared.

In the first group, STM included: (a) medications, (b) unstructured psychological support focused on socio-relational impairment, (c) rehabilitative interventions, and (d) specific MHS training in BPD treatment with regular supervisions. In the second group, SB-APP treatment was provided instead of unstructured psychological support. SB-APP group received the usual treatment plus SB-APP ( 40 weekly sessions) for 10 or 11 months. At the end of the first year $\left(\mathrm{T}_{12}\right)$, STM group continued with the as-usual management with supportive weekly sessions whilst the SB-APP group was carried on with psychiatric, nurse and educational management without any individual psychological support.

Clinical Global Impression (CGI; Guy, 1976) and CGI-modified (CGI-M; Perez, Barrachina, Soler, Pascual, Campins, Puigdemont, \& Alvarez, 2007) for BPD, Global Assessment of Functioning (GAF; APA, 2000), State-Trait Anger Expression Inventory (STAXI; Spielberger, 1996), and Symptom Checklist-90 Revised (SCL-90-R; Derogatis, Rickels, \& Rock, 1976) were repeatedly administered for two years at $\mathrm{T}_{1}, \mathrm{~T}_{3}, \mathrm{~T}_{6}, \mathrm{~T}_{12}, \mathrm{~T}_{18}$ and $\mathrm{T}_{24}$. At $\mathrm{T}_{12}$ the Working Alliance Inventory-Short Form (WAI-S; Horvath \& Greenberg, 1989) was also completed after one year. Four main results emerged from this study.

a) The branch of the study including specific MHS team supervision in addition to treatment-as-usual (STM) showed an improvement in the symptoms and social functioning compared to baseline, even though a structured psychotherapy was not applied. According to these results, a SB-APP treatment for BPD might be part of an articulated clinical project. MHS team were beneficially trained to provide their interventions in a manner consistent with psychotherapist's objectives. This is quite different, for example, from the setting of TFP (Doering et al., 2010), where the psychotherapist is available for the patients only during the sessions (as also happens in SB-APP), but other clinical tasks are less defined. SBAPP setting is also different from that of DBT (Linehan et al., 2006), in which training for clinicians is provided, but the psychotherapist is more available for the patients outside the sessions.

b) The improvement was found to be stable over time. These findings are consistent with those of DBT, CBT, MBT and TFP (Paris, 2010).

c) SB-APP was more effective than STM concerning some core psychopathological characteristics of BPD (disturbed relationships, impulsivity, suicidal/self-damaging behaviours, and chronic feelings of emptiness). Several treatments (Paris, 2010; Verheul \& Herbrink, 2007) are useful to address specific disruptive behaviours of severe BPD, but are less effective in reducing heavy MHS use related to intolerance of aloneness, conflicts over dependency (Choi-Kain et al., 2010) or the tendency of "pushing the limits" in building therapeutic alliance: All this produces a high rate of MHS use and great problems in BPD management. In the above study, SB-APP superiority to STM was possibly related to the specific setting and technique of the structured treatment compared to the unstructured psychological support (Amianto et al., 2011).

Distorted relationships may benefit in general from a well-structured treatment setting, whereas treating impulsivity and self-damaging behaviours needs an accurate identification with patients' cognitive and emotional patterns and defense mechanisms (Zanarini, 2009): This represents the SB-APP specific focus. Moreover, patients' feelings of emptiness are very persistent and have different psychopathological features during evolution of BPD (Gunderson, 2008). Consequently, SB-APP therapists address patients' emptiness with: promoting mentalization (at PFL 1), decreasing splitting defenses (at PFLs 2 and 3) and increasing tolerance for ambivalence (at PFL 4).

d) Furthermore, SB-APP was more effective in building a good and stable therapeutic relationship. Previous studies showed evidence that some specific psychosocial aspects are predictors of WA and 
psychotherapy outcome: quality of object relations (Piper et al., 1991), which characterizes the patient's lifelong pattern of relationships, recent interpersonal functioning (ibidem), and defense mechanisms (Hersoug, Sexton, \& Høglend, 2002). In patients with BPD, both quality of object relations (Gunderson, 2008) and defensive functioning (Perry \& Cooper, 1986) are poor. Moreover, process investigations on psychodynamic psychotherapies have already showed that WA is increased by therapist's technical interventions, when they are appropriately used, accordingly to the different level of defense mechanisms (Hersoug, 2004), as emphasized by SB-APP technique.

\section{Conclusion}

We may suggest that SB-APP, as a careful psychopathology-based psychotherapy, should be useful with severe borderline patients, even using a timelimited setting. Furthermore, SB-APP is a shorter (about 10 months) and less intensive (one weekly session) therapy, compared to other effective treatments. This could allow a good patient turnover, increasing MHS efficiency. Specifically concerning the end of psychotherapy, there is some evidence that setting a limit to the treatment duration could facilitate the patient's executive attention and increase WA (Levy, Beeney, Wasserman, \& Clarkin, 2010). Executive attention is specifically involved in the ability to regulate individuals' responses, particularly when they are in conflict situations where several solutions are possible (Johnson, 2005). Thus, an explicit time-limited setting in psychotherapy could help the patients not to see the end of treatment as an incomprehensible abandon.

However, therapists should be alerted about potential difficulties in working with a time-limited setting with BPD patients. More in detail, SB-APP modules did not show a significant improvement after the first year of follow-up. This may derive from resistances to change, which are typical of patients with severe personality disorders. If necessary, more than one module of SB-APP could be foreseen, in sequence, with different therapists and specific aims and strategies, accompanying the patient's needs and evolution. An adequate continuity of overall clinical care must also be provided, when needed.

SB-APP is overall focused on patient's psychopathology and is not only devoted to BPD treatment. Therefore, therapists have to be trained to carefully recognize PFLs of these patients, due to their nonhomogeneity. SB-APP treatment focus is thus somewhat different from the focus of: Mentalization Based Treatment (Bateman \& Fonagy, 2009), that is, levels of mentalization; Dialectical Behaviour Therapy (Linehan et al., 2006), that is, dialectical balance between acceptance and behaviour change; Transference Focused Psychotherapy (Doering et al., 2010), that is, transference dynamics; Cognitive
Behaviour Therapy (Davidson et al., 2006), that is, dysfunctional beliefs; Schema Focused Therapy (Giesen-Bloo, van Dyck, \& Spinhoven, 2006), that is, cognitive and emotional schemas; Interpersonal Psychotherapy (Bellino, Rinaldi, \& Bogetto, 2010), that is, relational dynamics; Supportive psychotherapy (Aviram, Hellerstein, Gerson, \& Stanley, 2004), that is, patient's level of impairment.

Nevertheless, also non-specific agents of structured time-limited psychotherapy (Paris, 2010), such as a specific setting and a more significant therapeutic relationship may be responsible for improved SB-APP outcome compared to unstructured psychological support in the treatment of BPD. Finally, larger samples and cost/effectiveness analyses are needed in order to compare SB-APP treatment to the TAU and/or other psychotherapies in the real context of MHS clinical practice.

\section{References}

Adler, A. (1971). Il temperamento nervoso [The nervous character]. Roma: Astrolabio.

Adler, A. (1970). Prassi e teoria della psicologia individuale [The practice and theory of individual psychology]. Roma: Newton Compton.

American Psychiatric Association (2000). Global Assessment of Functioning. Washington, DC: Author.

Amianto, F., Ferrero, A., Pierò, A., Cairo, E., Rocca, G., Simonelli, B., ... Fassino, S. (2011). Supervised team management, with or without structured psychotherapy, in heavy users of a mental health service with borderline disorder: A two-year follow-up preliminary randomized study. $B M C$ Psychiatry, 11, 181. Retrieved from http://www.biomedcentral.com/bmcpsychiatry/content.

Andrews, G., Singh, M., \& Bond, M. (1993). The Defense Style Questionnaire. Journal Nervous of Mental Disease, 181(4), 246-256.

Aviram, R. B., Hellerstein, D. J., Gerson, J., \& Stanley, B. (2004). Adapting supportive psychotherapy for individuals with Borderline personality disorder who self-injure orattempt suicide. Journal of Psychiatric Practice, 10(3), 145-155.

Bateman, A., \& Fonagy, P. (2009). Randomized controlled trial of outpatient mentalization-based treatment versus structured clinical management for borderline personality disorder. American Journal of Psychiatry, 166(12), 1355-1364.

Bellino, S., Rinaldi, C., \& Bogetto, F. (2010). Adaptation of interpersonal psychotherapy to borderline personality disorder: A comparison of combined therapy and single pharmacotherapy. Canadian Journal of Psychiatry 55(2), 74-81.

Bender, D. S. (2005). The therapeutic alliance in the treatment of personality disorders. Journal of Psychiatric Practice, 11(2), 73-87.

Bender, D. S., \& Skodol, A. E. (2007). Borderline personality as self-other representational disturbance. Journal of Personality Disorders, 21(5), 500-517.

Bender, D. S., Skodol, A. E., Pagano, M. E., Dyck, I. R., Grilo, C. M., Shea, M. T., Sanislow, C. A., Zanarini, M. C., Yen, S., McGlashan, T. H., \& Gunderson, J. G. (2006). Prospective assessment of treatment use by patients with personality disorders. Psychiatric Services, 57, 254-257.

Bolterauer, L. (1982). Die narzisstisch gestörte Persönlichkeit im psychoanalytischen Aspekt von $\mathrm{H}$. Kohut und im 
individualpsychologischen Aspekt von F. Künkel [The narcissistically disturbed personality from the psychoanalytic perspective of $\mathrm{H}$. Kohut and from the individual psychological perspective of F. Künkel]. Zeitschrift für Individualpsychologie, 7, 76-84.

Bond, M., \& Perry, J. C. (2004). Long-term changes in defense styles with psychodynamic psychotherapy for depressive, anxiety and personality disorders. American Journal of Psychiatry, 161(9), 1665-1671.

Bowins, B. (2010). Personality disorders: A dimensional defense mechanism approach. American Journal of Psychotherapy, 64(2), 153-169.

Caligor, E., \& Clarkin, J. F. (2010). An object relations model of personality and personality pathology. In J. F. Clarkin, P. Fonagy, \& G. O. Gabbard (Eds.), Psychodynamic psychotherapy for personality disorders: A clinical handbook (pp. 3-35). Washington, DC: American Psychiatric Publishing.

Choi-Kain, L. W., Fitzmaurice, G. M., Zanarini, M. C., Laverdière, O., \& Gunderson, J. G. (2009). The relationship between self-reported attachment styles, interpersonal dysfunction, and borderline personality disorder. Journal of Nervous and Mental Disease, 197, 816-821.

Choi-Kain, L. W., Zanarini, M. C., Frankeburg, F. R., Fitzmaurice G. M., \& Reich, D. B. (2010). A longitudinal study of the 10-year course of interpersonal features in borderline personality disorder. Journal of Personality Disorders, 24(3), 356-376.

Davidson, K. M., Norrie, J., Tyrer, P., Gumley, A., Tata, P., Murray, H., \& Palmer, S. J. (2006). The effectiveness of cognitive behaviour therapy for borderline personality disorder: Results from borderline personality disorder study on cognitive therapy (ВОSСОТ) trial. Journal of Personality. Disorders, 20(5), 450-465.

Delaney, J. C., Yeomans, F., Stone, M. H., \& Haran, C. (2008). Some factor affecting treatment outcome in a randomized clinical trial of borderline patients. Santé Mentale au Quebec, 33(1), 15-36.

Derogatis, L. R., Rickels, K., \& Rock, A. F. (1976). The SCL 90 and the MMPI: A step in the validation of a new selfreport scale. British Journal of Psychiatry, 128, 280-289.

Distel, M. A., Willemsen, G., Lightart, L., Derom, C. A., Martin, N. G., Neale, M. C., Trull, T. J., \& Boomsma, D. I. (2010). Genetic covariance structure of the four main features of borderline personality disorder. Journal of Personality Disorders, 24(4), 427-444.

Doering, S., Hörz, S., Rentrop, M., Fischer-Kern, M., Schuster, P., Benecke, C., ... Buchheim, P. (2010). Transference-focused psychotherapy treatment $v$. treatment by community psychotherapists for borderline personality disorder: Randomized controlled trial. British Journal of Psychiatry, 196(5), 389-395.

Driessen, M., Beblo, T., Reddemann, L., Rau, H., Lange, W., Silva, A., Berea, R. C., Wulff, H., \& Ratzka, S. (2002). Ist die Borderline-Persönlichkeitsstörung eine komplexe posttraumatische Störung? Zum Stand der Forschung [Is the borderline disorder a complex post-traumatic stress disorder? The state of research]. Nervenarzt, 73(9), 820-829.

Dziobek, I., Preißler, S., Grozdanovic, Z., Heuser, I., Heekeren, H. R., \& Roepke, S. (2011). Neuronal correlates of altered empathy and social cognition in borderline personality disorder. Neuroimage, 57(2), 539-548.

Fassino, S., Abbate Daga, G., \& Leombruni, P. (2007). Manuale di psichiatria biopsicosociale [Manual of biopsychosocial psychiatry]. Torino: CSE.

Fassino, S., Amianto, F., \& Ferrero, A. (2008). Brief Adlerian Psychodynamic Psychotherapy: Theoretical issues and process indicators. PanMinerva Medica, 50(2), 165-175.

Ferrero, A. (1995). Insula dulcamara: Studi di psicologia e psichiatria psicodinamica [Insula dulcamara: Studies in psychology and psychodynamic psychiatry]. Torino: CSE.

Ferrero, A. (2009). Psicoterapia Psicodinamica Adleriana (APP): Un trattamento possibile nei Dipartimenti di Salute Mentale [Psychodynamic Adlerian Psychotherapy (APP): A possible treatment in Departments of Mental Health]. Torino: CSRP Edizioni.

Ferrero, A., \& Simonelli, B. (2006). Sequential BriefAdlerian Psychodynamic Psychotherapy (SB-APP): Psicoterapia time-limited per pazienti con organizzazione borderline di personalità [Sequential Brief-Adlerian Psychodynamic Psychotherapy (SB-APP): Time-limited psychotherapy for patients with borderline personality organization]. Rivista di Psicologia Individuale, 59, 13-38.

Fonagy, P., Luyten, P., Batenian, A., Gergely, G., Strathearn, L., Target, M., \& Allison, E. (2010). Attachment and personality pathology. In J. F. Clarkin, P. Fonagy, \& G. O. Gabbard (Eds.), Psychodynamic psychotherapy for personality disorders. A clinical handbook. Washington, DC: American Psychiatric Publishing.

Fonagy, P., \& Target, M. (2007). The rooting of the mind in the body: New links between attachment theory and psychoanalytic thought. Journal of American Psychoanalytic Association, 55(2), 411-456.

Gabbard, G. O. (2000). Psychodynamic psychiatry in clinical practice. Arlington: American Psychiatric Press.

Giesen-Bloo, J., van Dyck, R., \& Spinhoven, P. (2006). Outpatient psychotherapy for borderline personality disorder: Randomized trial of schema focused therapy vs. Transference focused psychotherapy. Archives of General Psychiatry, 63(6), 649-658.

Goodman, M., New, A., \& Siever, L. (2004). Trauma, genes, and the neurobiology of personality disorders. Annals of the New York Academy of Sciences, 1032, 104-116.

Gorton, G. E. (2000). Psychodynamic approaches to the patient. Psychiatric Services, 51, 408-409.

Gunderson, J. G. (2008). Borderline personality disorder: A clinical guide. ( $2^{\text {nd }}$ ed.). Arlington: American Psychiatric Publishing.

Gunderson, J. G., Stout, R. L., McGlashan, T. H., Shea, M. T., Morey, L. C., Grilo, C. M., Zanarini, M. C., Yen, S., Markowitz, J. C., Sanislow, C., Ansell, E., Pinto, A., \& Skodol, A. E. (2011). Ten-year course of Borderline Personality Disorder: Psychopathology and function from the collaborative longitudinal personality disorders study. Archives of General Psychiatry, 68(8), 827-837.

Guy, W. (1976). ECDEU Assessment Manual for Psychopharmaology. DHEW Publication, No. (ADM) 76-338.

Hadjipavlou, G., \& Ogrodniczuk, J. S. (2010). Promising psychotherapies for personality disorders. Canadian Journal of Psychiatry, 55(4), 202-210.

Herpertz, S. C. (2011). Contribution of neurobiology to our knowledge of borderline personality disorder. Nervenarzt, 82(1), 9-15.

Hersoug, A. G. (2004). Assessment of therapists' and patients' personality: Relationship to therapeutic technique and outcome in brief dynamic psychotherapy. Journal of Personality Assessment, 83(3), 191-200.

Hersoug, A. G., Høglend, P., \& Bøgwald, K. P. (2004). Is there an optimal adjustment of interpretation on the patients' level of defensive functioning? American Journal of Psychotherapy, 58(3), 349-361.

Hersoug, A. G., Sexton, H. C., \& Høglend, P. (2002). Contributions of defensive functioning to the quality of working alliance and psychotherapy outcome. American Journal of Psychotherapy, 56, 539-554.

Horvath, A. O., \& Greenberg, L. S. (1989). Development and validation of the Working Alliance Inventory. Journal of Counseling Psychology, 36, 223-233.

Johnson, M. H. (2005). Developmental cognitive neuroscience. 
Oxford: Blackwell.

Jørgensen, C. R. (2006). Disturbed sense of identity in borderline personality disorder. Journal of Personality Disorders, 20(6), 618-644.

Jørgensen, C. R. (2010). Invited essay: Identity and borderline personality disorder. Journal of Personality Disorders, 24(3), 344-364.

Kendler, K. S., Aggen, S. H., Czajkowski, N., Røysamb, E., Tambs, K., Torgesen, S., Neale, M. C., \& ReichbornKjennerud, T. (2008). The structure of genetic and environmental risk factor for DSM-IV personality disorder: A multivariate twin study. Archives of General Psychiatry, 65(12), 1438-1446.

Kernberg, P. F. (1994). Mechanisms of defense: Development and research perspectives. Bulletin of Menninger Clinic, 58(1), 55-87.

Kerr, I. B., Dent-Brown, K., \& Parry, G. D. (2007). Psychotherapy and mental health teams. International Review of Psychiatry, 19, 63-80.

Koekkoek, B., van Meijel, B., Schene, A., \& Hutschemaekers, G. (2009). Problems in psychiatric care of 'difficult patients': A Delphi-study. Epidemiologia e Psichiatria Sociale, 18, 323-330.

Koenigsberg, H. V. (2009). Neural correlates of borderline personality disorder symptoms. Paper presented at the International Society for the Study of Personality Disorders, New York.

Lasch, C. (1991). The culture of narcissism: Life in an age of diminishing expectations. New York: Norton.

Leibovich, M. A. (1983). Why short-term psychotherapy for borderlines? Psychotherapy and Psychosomatics, 39, 1-9.

Leichsenring, F. (2005). Are psychodynamic and psychoanalytic therapies effective? A review of empirical data. International Journal of Psychoanalysis, 86(3), 841-868.

Leichsenring, F., Leibing, E., Kruse, J., New, A. S., \& Leweke, F. (2011). Borderline personality disorder. Lancet, 377(9759), 74-84.

Lenzenweger, M. F., Clarkin, J. F., Yeomans, F. E., Kernberg, O. F., \& Levy, K. N. (2008). Refining the borderline personality disorder phenotype through finite mixture modeling: Implications for classification. Journal of Personality Disorders, 22(4), 313-331.

Levy, K. N., Beeney, J. E., Wasserman, R. H., \& Clarkin, J. F. (2010). Conflict begets conflict: Executive control, mental state vacillations, and the therapeutic alliance in treatment of borderline personality disorder. Psychotherapy Research, 15, 1-10.

Limberg, A., Barnow, S., Freyberger, H. J., \& Hamm, A. O. (2011). Emotional vulnerability in borderline personality disorder is cue specific and modulated by traumatization. Biological Psychiatry, 69(6), 574-582.

Linehan, M. M., Comtois, K. A., Murray, A. M., Brown, M. Z., Gallop, R. J., Heard, H. L., Korslund, K. E., Tutek, D. A., Reynolds, S. K., \& Lindenboim, N. (2006). Two-year randomized controlled trial and follow-up of dialectical behavior therapy $v s$ therapy by experts for suicidal behaviors and borderline personality disorder. Archives of General Psychiatry, 63(7), 757-766.

Lingiardi, V., Lonati, C., Delucchi, F., Fossati, A., Vanzulli, L., \& Maffei, C. (1999). Defense mechanisms and personality disorders. Journal of Nervous and Mental Disease, 187(4), 224-228.

Lingiardi, V., \& Madeddu, F. (2002). I meccanismi di difesa: Teoria, valutazione, clinica [Defense mechanisms: Theory, asessment, practice]. Milano: Raffaello Cortina.

Lingiardi, V., Colli, A., Gentile, D., \& Tanzilli, A. (2011). Exploration of session process: Relationship to depth and alliance. Psychotherapy, 48(4), 391-400.

Livesley, J. (2008). Toward a genetically-informed model of borderline personality disorder. Journal of. Personality Disorders, 22(1), 42-71.

Matschiner-Zollner, M. (2004). Szenisches Verstehen im Lichte neuer Theorien. Projective Identifizierung, Rollenspielbereitschaft, Enactmenttheorien: Drei Beiträge zu einem erweiteren Verständnis des szenischen Verstehens im Erstinterview [Scenic understanding in the light of new theories. Projective identification, role-playing readiness, enactment theories: Three contributions to a wider understanding of the scenic understanding in first interview]. Zeitschrift für Individualpsychologie, 29, 322-343.

Mc Closkey, M. S., New, A. S., Siever, L. J., Goodman, M., Koenigsberg, H. V., Flory, J. D., \& Coccaro, E. F. (2009). Evaluation of behavioral impulsivity and aggression tasks as endophenotypes for borderline personality disorder. Journal of Psychiatric Research, 43(12), 1036-1048.

Morbach, W. (2007). Die geteilte Wirklichkeit: Zur interaktionellen Dynamik der Abwehrmechanismen [The shared reality: On the interactional dynamics of defence mechanisms]. Zeitschrift für Individualpsychologie, 32, 107-126.

National Institute for Clinical Excellence (2009). Borderline personality disorder clinical guidance. Treatment and management. NICE clinical guideline 78. London: Author.

Paris, J. (2007). Intermittent psychotherapy: An alternative to continuous long-term treatment for patients with personality disorders. Journal of Psychiatric Practice, 13(3), 153158.

Paris, J. (2010). Effectiveness of different psychotherapy approaches in the treatment of borderline personality disorder. Current Psychiatry Reports, 12, 56-60.

Perez, V., Barrachina, J., Soler, J., Pascual, J. C., Campins, M. J., Puigdemont, D., \& Alvarez, E. (2007). The clinical global impression scale for borderline personality disorder patients (CGI-BPD): A scale sensible to detect changes. Actas Españolas de Psiquiatria, 35, 229-235.

Perry, J. C., \& Cooper, S. H. (1986). A preliminary report on defences and conflicts associated with borderline personality disorder. Journal of American Psycoanalytic Association, 34(4), 863-893.

Piper, W. E., Azim, H. F., Joyce, A. S., Mc Callum, M., Nixon, G. W., \& Segal, P. S. (1991). Quality of objects relations versus interpersonal functioning as predictors of therapeutic alliance and psychotherapy outcome. Journal of Nervous and Mental Disease, 179, 432-438.

Piper, W. E., Ogrodniczuk, J. S., \& Joyce, A. S. (2004). Quality of object relations as a moderator of the relationship between pattern of alliance and outcome in short-term individual psychotherapy. Journal of Personality Assessment, 83(3), 345-356.

Presniak, M. D., Olson, T. R., \& Macgregor, M. W. (2010). The role of defense mechanisms in borderline and antisocial personalities. Journal of Personality Assessment, 92(2), 137-145.

Presslich-Titscher, E. (1997). Borderline-Störungen: Wenn Gefühle abgespalten werden müssen [When emotions must be split off]. Zeitschrift für Individualpsychologie, 22, 32-37.

Rovera, G. G. (Ed.). (1996). Il paziente borderline: Aspetti clinici, psicopatologici e terapeutici [The borderline patient: Clinical, psychopathological, and therapeutical aspects]. Torino: CSE.

Siever, L. J., \& Weinstein, L. N. (2009). The neurobiology of personality disorders: Implications for psychoanalysis. Journal of American Psychoanalytic Association, 57(2), 361-398.

Shedler, J., \& Westen, D. (1998). Refining the measurement of Axis II: A Q-sort procedure for assessing personality pathology. Assessment, 5, 333-353.

Sledge, W. H., Moras, K., Hartley, D., \& Levine, M. (1990). Effect of time-limited psychotherapy on patient dropout rates. American Journal of Psychiatry, 147, 1341-1347.

Spielberger, C. D. (1996). State-Trait Anger Expression Inven- 
tory: Professional manual. Odessa, FL: Psychological Assessment Resources.

Steele, H., \& Siever, L. (2010). An attachment perspective on borderline personality disorder: Advances in geneenvironment considerations. Current Psychiatry Reports, 12(1), 61-67.

Stoffers, J., Völlm, B. A., Rücker, G., Timmer, A., Huband, N., \& Lieb, K. (2010). Pharmacological interventions for borderline personality disorder. Cochrane Database Systematic Reviews, 16(6), CD005653.

Sundbom, E., Jacobsson, L., Kullgren, G., \& Penavo, U. (1998). Personality and defenses: A cross-cultural study of psychiatric patients and healthy individuals in Nicaragua and Sweden. Psychological Reports, 83(3), 1331-1347.

Svrakic, D. M., Lecic-Tosevski, D., \& Divac-Jovanovic, M. (2009). DSM axis II: Personality disorders or adaptation disorders? Current Opinion in Psychiatry, 22(1), 111-117.

Tenbrink, D. (1998). Betrachtungen zum Spannungsfeld zwischen individualpsychologischer Identität und psychoanalytischen Selbstverständnis in der Individualpsychologie [Reflections on the tension between individual psychological identity and psychoanalytic self-concept in individual psychology]. Zeitschrift für Individualpsychologie, 23, 95-115.

Vaillant, G. E., Bond, M., \& Vaillant, C. O. (1986). An empirically validated hierarchy of defense mechanisms. Archives of General Psychiatry, 43, 786-794.

Van Asselt, A. D., Dirksen, C. D., Arntz, A., \& Severens, J. L. (2007). The cost of borderline personality disorder: Societal cost of illness in BPD-patients. European Child and Adolescent Psychiatry, 22, 354-361.

Verheul, R., \& Herbrink, M. (2007). The efficacy of various modalities of psychotherapy for personality disorders: A system- atic review of the evidence and clinical recommendations. International Review of Psychiatry, 19(1), 25-38.

Weinberg, I., Rønningstam, E., Goldblatt, M. J., Schechter, M. Wheelis, J., \& Maltsberger, J. T. (2010). Strategies in treatment of suicidality: Identification of common and treatment-specific interventions in empirically supported treatment manuals. Journal of Clinical Psychiatry, 71(6), 699-706.

White, K. (2007). Nach der Tat. Das Durcharbeiten von Therapieabbrüchen in der Gegenübertragung [After the fact: The working-through of thearpy dropouts in the countertransference]. Zeitschrift für Individualpsychologie, 32, 135153.

Wolf, R. C., Sambataro, F., Vasic, N., Schmid, M., Thomann, P. A., Bienentreu, S. D., \& Wolf, N.D. (2011). Aberrant connectivity of resting-state networks in borderline personality disorder. Journal of Psychiatry and Neuroscience, 36(2), 100-150.

Zanarini, M. C. (2009). Psychotherapy of borderline personality disorder. Acta Psychiatrica Scandinavica, 20, 373-377.

Zanarini, M. C., \& Frankenburg, F. R. (2007). The essential nature of borderline psychopathology. Journal of Personality Disorders, 21(5), 518-535.

Zanarini, M. C., Weingeroff, J. L., \& Frankenburg, F. R. (2009). Defense mechanisms associated to Borderline Personality Disorder. Journal of Personality Disorders, 23(2), 113-121.

Received April 15, 2012

Revision received September 18, 2012

Accepted October 13, 2012 